\title{
Conceptual Design of a Fischer-Tropsch Reactor in a Gas-to-Liquid Process
}

\author{
Hyun-Jung Lee, ${ }^{\dagger}$ Ju-Hwan Choi, ${ }^{\ddagger}$ Arthur Garforth, ${ }^{\dagger}$ and Sungwon Hwang*, \\ ${ }^{\dagger}$ School of Chemical Engineering and Analytical Science, The University of Manchester, P.O. Box 88, Manchester, M60 1QD, \\ United Kingdom \\ ${ }^{*}$ Department of Chemistry and Chemical Engineering, Inha University, 253, Yonghyun-Dong, Nam-Gu, Incheon, South Korea
}

ABSTRACT: This research focused on the design and optimization of a two-phase Fischer-Tropsch (F-T) reactor in a gas-toliquid (GTL) process. For the design of the F-T reactor, the overall process configuration was developed using Aspen HYSYS software. Various reaction mechanisms for the F-T process over iron-based catalysts were reviewed from the published literature. The F-T kinetics was adopted for reactor modeling, and the reaction kinetic parameters were adjusted to increase the accuracy of the modeling results. Furthermore, the effects of catalyst size, catalyst active sites, and reactor configuration were embedded into the modeling. The yields of the F-T process were analyzed under various operating conditions. Finally, operating conditions, such as the temperature and pressure of the two-phase-reactor model, were optimized to maximize the yield of hydrocarbon products.

\section{INTRODUCTION}

When oil prices increased rapidly, technologies for the production of synthetic fuel from natural gas or coal attracted interest from academia and industry. For example, gas-to-liquid (GTL) processes have received much attention from a number of researchers, since the process converts natural gas into highpriced, environmentally friendly fuels (i.e., naphtha, gasoline, kerosene, and diesel).

In fact, synthetic fuel from the GTL process has many advantages compared with other processes. These advantages include (1) lower transportation cost of the final liquid product compared with the gaseous form, (2) high cetane value of the diesel product due to its low aromatic content, (3) environmentally friendly fuel with almost zero sulfide components, and (4) high capability to utilize stranded gas located far from a demand area, without the need for special transportation facilities. Industrial experts expect that GTL fuels will lessen the dependence on foreign oil and reduce environmental problems. Furthermore, due to the high quality of transportation fuels derived from the GTL process, the product oil could be sold at a higher price than conventional crude-oilderived fuels. For example, at crude oil prices of $\$ 16-18$ per barrel, it is estimated that GTL-derived oil may be sold at a price of $\$ 22-25$ per barrel. ${ }^{1}$

Over the past few decades, various companies and research institutes have attempted to develop the GTL process, including those exploiting the process commercially. For example, SASOL and Shell gained experience using their own GTL technologies on a commercial scale for several years. EXXON also proved its technology in pilot plants and was ready to implement it on a commercial scale. Williams Energy, Syntroleum, Statoil, and Rentech each claimed to have their own technologies as well. Despite these activities, the GTL process has not yet been fully commercialized. ${ }^{2}$

The standard GTL plant process includes three main steps, viz., (1) syngas production, (2) Fischer-Tropsch (F-T) synthesis, and (3) product upgrading and separation. High value added products are usually obtained by upgrading the F-T products using established refinery processes, such as hydrocracking and isomerization. Figure 1 shows a block diagram of the overall GTL plant configuration and the related chemical processes.

For the production of synthesis gas, various reforming reactions have been developed, as shown below.

steam reforming of methane (SRM):

$$
\mathrm{CH}_{4}+\mathrm{H}_{2} \mathrm{O}=\mathrm{CO}+3 \mathrm{H}_{2}
$$

carbon dioxide reforming of methane (CDR):

$$
\mathrm{CH}_{4}+\mathrm{CO}_{2}=2 \mathrm{CO}+2 \mathrm{H}_{2}
$$

partial oxidation of methane (POX):

$$
\mathrm{CH}_{4}+0.5 \mathrm{O}_{2}=\mathrm{CO}+2 \mathrm{H}_{2}
$$

On the basis of the above reactions, mainly the following three different types of reforming process technologies have been developed so far.

catalytic partial oxidation (CPO): POX on catalysts

autothermal reforming (ATR): SRM + POX

tri-reforming: $\mathrm{SRM}+\mathrm{POX}+\mathrm{CDR}$

Subsequently, the synthesis gas is converted to hydrocarbons using F-T reactions, as presented in the following reaction mechanisms.

$$
n \mathrm{CO}+(2 n+1) \mathrm{H}_{2}=\mathrm{C}_{n} \mathrm{H}_{2 n+2}+n \mathrm{H}_{2} \mathrm{O}
$$

Received: February 10, 2015

Revised: May 16, 2015

Accepted: June 11, 2015

Published: June 11, 2015 


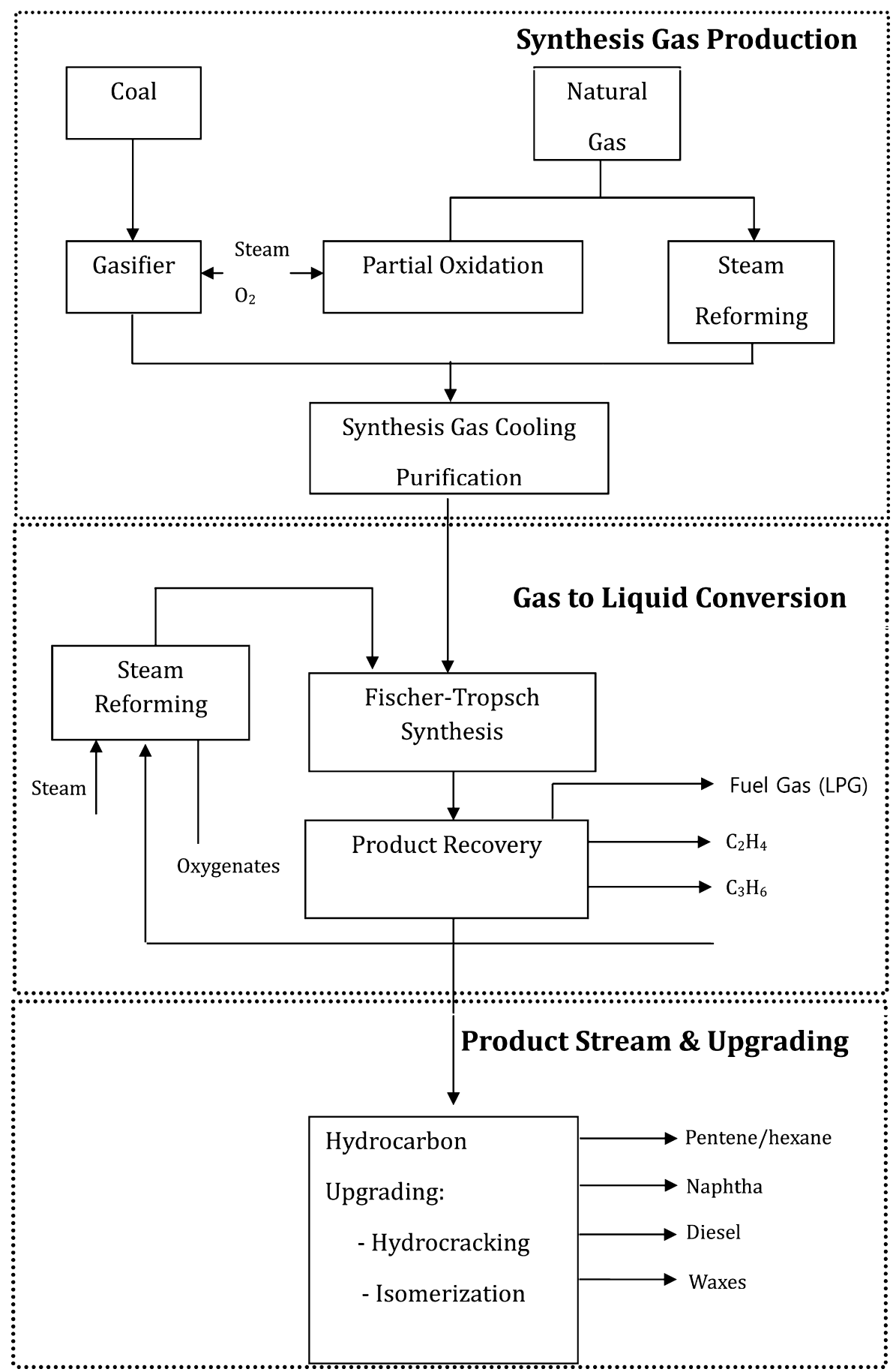

Figure 1. Overall process scheme of a conventional GTL plant.

$$
\begin{aligned}
& n \mathrm{CO}+2 n \mathrm{H}_{2}=\mathrm{C}_{n} \mathrm{H}_{2 n}+n \mathrm{H}_{2} \mathrm{O} \\
& \mathrm{C}_{n} \mathrm{H}_{2 n}+\mathrm{H}_{2} \mathrm{O}=\mathrm{C}_{n} \mathrm{H}_{2 n+2} \mathrm{O}
\end{aligned}
$$

Equation 4 refers to the production of paraffins, and eq 5 refers to the production of olefins. Alcohol products (eq 6) are formed either as byproducts or as main products, depending on the type of catalytically active metal and the operating pressure of the reactor. In addition to these reactions, other negligible side reactions might exist, but this research did not consider them. Catalyst selectivity, syngas composition, and process operating conditions mainly govern the product distribution and the limit of the paraffinic chain length. In addition, F-T reactions are highly exothermic; therefore, the heat generated by the reaction needs to be removed rapidly in order to avoid the undesired formation of high levels of methane and light hydrocarbons.

Many researchers have focused on the reforming step and have developed standard reforming kinetics under various process conditions. On the other hand, the F-T step remains in the development stage due to the high complexity of its reaction mechanism, thus creating difficulties for researchers. First, detailed mechanisms of the F-T reaction have not been fully identified. Second, the design and scale-up of a commercial F-T synthesis reactor have not been fully established on the basis of the kinetic models. To estimate the performance of the F-T process, an accurate comprehensive kinetic model that describes 
the product distribution of F-T synthesis must be developed. Meanwhile, only a few researchers have worked on identification of the F-T reaction mechanisms and development of identified reaction kinetics. As a result, a reactor in the F-T process was not designed properly on the basis of the reaction kinetics, and the reactor design and operating parameters were not fully optimized.

For this reason, this research focused on (1) identifying F-T reaction kinetics, (2) developing accurate models to estimate hydrocarbon distributions in the main products, and (3) optimizing the reaction conditions to maximize hydrocarbon products. Specifically, this research attempts to maximize gasoline (C4-C8) and gas oil (C9-C20) products by optimizing reactoroperating conditions, since the sale of these products commands a high profit from the market.

\section{BACKGROUND}

Over the past decades, researchers have studied various reactors for F-T process and mostly used a single-phase reactor model. Slurry bed columns for F-T were first commercialized by SASOL in the 1980s. The corresponding reactor model was first investigated by Van der Laan, who modeled the F-T reactions using an iron-based catalyst in 1999. Van der Laan established a model in which olefin readsorption depended on the chain length, a result of the increasing solubility of long chain hydrocarbons in the liquid phase. ${ }^{3}$ More recently, a new product characterization model has been proposed by Botes for ironbased, low-temperature F-T synthesis. ${ }^{4} \mathrm{He}$ proposed a model that successfully described the olefin and paraffin distributions in the $\mathrm{C} 3+$ range, excluding methane and ethane. This model also considers the readsorption of olefins, as well as secondary reactions that mainly include chain growth to higher hydrocarbons and hydrogenation to corresponding paraffins. In addition, he reported that chain length dependent effects could be described by olefin reincorporation, in which the propensity for secondary reactions increases with an increasing carbon number. The reasons for this proposed dependency of secondary reactions on chain length include (1) slower diffusion of longer molecules through catalyst pores, (2) higher concentration of heavier olefins in the liquid phase because of an increase in solubility with longer chain length, (3) stronger physisorption of longer molecules on the catalyst surface, and (4) variations in reactor residence times because of the different solubilities in the liquid phase. ${ }^{4}$ However, this model suffers from limitations at low-temperature conditions. Schulz et al. developed an olefin reincorporation model based mainly on chain length, which was dependent on the product solubility. ${ }^{5}$ However, their model was compared only to a very limited number of experimental products, which were not enough to evaluate the olefin mass transfer effects.

The kinetics models of Yang $^{6}$ for two-phase reactors were considered in this work. According to Yang, the formation rates of paraffins and olefins with $n$ carbons can be described as shown in eqs $7-9$.

$$
\begin{aligned}
& \mathrm{d} P(1) / \mathrm{d} t=k_{\text {met }}\left[\mathrm{CH}_{3} \mathrm{~s}\right]\left[\mathrm{Hs}_{1}\right]=k_{\text {met }} K_{5}\left[\mathrm{CH}_{2} \mathrm{~s}\right][\mathrm{Hs}]^{2} /[\mathrm{s}] \\
& \mathrm{d} P(n) / \mathrm{d} t=k_{\mathrm{p}}\left[\mathrm{C}_{n} \mathrm{H}_{2 n+1} \mathrm{~s}\right][\mathrm{Hs}]=\frac{k_{\mathrm{p}} K_{5}\left[\mathrm{C}_{n} \mathrm{H}_{2 n} \mathrm{~s}\right][\mathrm{Hs}]^{2}}{[\mathrm{~s}]} \quad(n \geq 2
\end{aligned}
$$

$$
\mathrm{d} P^{=}(n) / \mathrm{d} t=k_{\mathrm{o}}\left[\mathrm{C}_{n} \mathrm{H}_{2 n} \mathrm{~s}\right]-k_{-\mathrm{o}} P_{\mathrm{C}_{n} \mathrm{H}_{2 n}}[\mathrm{~s}] \quad(n \geq 2)
$$

Equation 10 gives the chain growth factor for carbon number $n$.

$$
\begin{aligned}
\alpha_{n} & =\frac{\left[\mathrm{C}_{n} \mathrm{H}_{2 n} \mathrm{~s}\right]}{\left[\mathrm{C}_{n-1} \mathrm{H}_{2 n-2} \mathrm{~s}\right]} \\
= & \frac{k_{\mathrm{CG}} K_{4} \frac{P_{\mathrm{H}_{2}}{ }^{2} P_{\mathrm{CO}}}{P_{\mathrm{H}_{2} \mathrm{O}}}[\mathrm{s}]}{k_{\mathrm{CG}} K_{4} \frac{\mathrm{P}_{\mathrm{H}}{ }^{2} P_{\mathrm{CO}}}{P_{\mathrm{H}_{2} \mathrm{O}}}[\mathrm{s}]+k_{\mathrm{p}} K_{5} K_{2} P_{\mathrm{H}_{2}}[\mathrm{~s}]+k_{\mathrm{o}}\left(1-\beta_{n}\right)} \\
\alpha_{\mathrm{A}} & =\frac{k_{\mathrm{CG}}\left[\mathrm{CH}_{2} \mathrm{~s}\right]}{k_{\mathrm{CG}}\left[\mathrm{CH}_{2} \mathrm{~s}\right]+k_{\mathrm{p}} K_{5} K_{2} P_{\mathrm{H}_{2}}[\mathrm{~s}]+k_{\mathrm{o}}} \\
& =\frac{k_{\mathrm{CG}} K_{4} \frac{P_{\mathrm{H}_{2}}{ }^{2} P_{\mathrm{CO}}}{P_{\mathrm{H}_{2} \mathrm{O}}}[\mathrm{s}]}{k_{\mathrm{CG}} K_{3}^{\prime} \frac{P_{\mathrm{H}_{2}}{ }^{2} P_{\mathrm{CO}}}{P_{\mathrm{H}_{2} \mathrm{O}}}[\mathrm{s}]+k_{\mathrm{p}} K_{5} K_{2} P_{\mathrm{H}_{2}}[\mathrm{~s}]+k_{\mathrm{o}}}
\end{aligned}
$$

The readsorption factors for 1-olefin with carbon number $n$ $(n \geq 2)$ are defined as follows:

$$
\begin{aligned}
& \beta_{n}=\frac{k_{-\mathrm{o}}}{k_{\mathrm{o}}}\left\{P_{\mathrm{C}_{n} \mathrm{H}_{2 n}} / \alpha_{\mathrm{A}}^{n-1} K_{4} \frac{P_{\mathrm{H}_{2}}^{2} P_{\mathrm{CO}}}{P_{\mathrm{H}_{2} \mathrm{O}}}\right. \\
& +\frac{k_{-\mathrm{o}}}{k_{\mathrm{CG}} K_{4} \frac{P_{\mathrm{H}_{2}}{ }^{2} P_{\mathrm{CO}}}{P_{\mathrm{H}_{2} \mathrm{O}}}[\mathrm{s}]+k_{\mathrm{p}} K_{5} K_{2} P_{\mathrm{H}_{2}}[\mathrm{~s}]+k_{\mathrm{o}}} \\
& \left.\left.\times \sum_{i=2}^{n} \alpha_{\mathrm{A}}^{i-2} P_{\mathrm{C}_{(n-i+2)} \mathrm{H}_{2(n-i+2)}}\right]\right\} \quad(n \geq 2)
\end{aligned}
$$

The concentration of free active site, $[\mathrm{s}]$, can be expressed as follows

$$
\begin{aligned}
{[\mathrm{s}]=} & 1 /\left[+\sqrt{K_{4} P_{\mathrm{H}_{2}}}+K_{1} P_{\mathrm{CO}}+K_{3}^{\prime} \frac{P_{\mathrm{H}_{2}}{ }^{2} P_{\mathrm{CO}}}{P_{\mathrm{H}_{2} \mathrm{O}}}\right. \\
& +K_{1} K_{2} P_{\mathrm{CO}} P_{\mathrm{H}_{2}}+K_{6} K_{4}{ }^{0.5} \mathrm{~K}_{3}^{\prime} \frac{P_{\mathrm{H}_{2}}^{2.5} P_{\mathrm{CO}}}{P_{\mathrm{H}_{2} \mathrm{O}}} \\
& +K_{3}^{\prime} \frac{P_{\mathrm{H}_{2}}{ }^{2} P_{\mathrm{CO}}}{P_{\mathrm{H}_{2} \mathrm{O}}} \sum_{i=2}^{n} \prod_{j=2}^{i}\left(\alpha_{j}\right) \\
& \left.+K_{6} K_{4}{ }^{0.5} \mathrm{~K}_{3}^{\prime} \frac{P_{\mathrm{H}_{2}}{ }^{2.5} P_{\mathrm{CO}}}{P_{\mathrm{H}_{2} \mathrm{O}}} \sum_{i=2}^{n} \prod_{j=2}^{i}\left(\alpha_{j}\right)\right]
\end{aligned}
$$

$$
\begin{aligned}
\frac{\mathrm{d} P(1)}{\mathrm{d} t}= & k_{\mathrm{met}} K_{2} K_{5} K_{4} \frac{P_{\mathrm{H}_{2}}{ }^{3} P_{\mathrm{CO}}}{P_{\mathrm{H}_{2} \mathrm{O}}} \\
& {\left[1+\sqrt{K_{2} P_{\mathrm{H}_{2}}}+K_{1} P_{\mathrm{CO}}+K_{4} \frac{P_{\mathrm{H}_{2}}{ }^{2} P_{\mathrm{CO}}}{P_{\mathrm{H}_{2} \mathrm{O}}}\right.} \\
& +K_{1} K_{3} P_{\mathrm{CO}} P_{\mathrm{H}_{2}}+K_{5} K_{4} K_{2}{ }^{0.5} \frac{P_{\mathrm{H}_{2}}{ }^{2.5} P_{\mathrm{CO}}}{P_{\mathrm{H}_{2} \mathrm{O}}} \\
& \left.+K_{4} \frac{P_{\mathrm{H}_{2}}{ }^{2} P_{\mathrm{CO}}}{P_{\mathrm{H}_{2} \mathrm{O}}}\left(1+K_{5} \sqrt{K_{2} P_{\mathrm{H}_{2}}}\right) \sum_{i=2}^{n} \prod_{j=2}^{i}\left(\alpha_{j}\right)\right]^{2}
\end{aligned}
$$


Table 1. Parameter Values of the F-T Mechanism, Proposed by Yang ${ }^{6}$

\begin{tabular}{|c|c|c|c|}
\hline parameter & value & parameter & value \\
\hline$K_{\mathrm{CG}}$ & $7.88 \times 10^{3} \mathrm{~mol} / \mathrm{g} \cdot \mathrm{s} \cdot \mathrm{bar}$ & $k_{\mathrm{CO}}$ & $3.42 \mathrm{~mol} / \mathrm{g} \cdot \mathrm{s} \cdot \mathrm{bar}^{1.5}$ \\
\hline$E_{\mathrm{CG}}$ & $75.52 \mathrm{~kJ} / \mathrm{mol}$ & $E_{\mathrm{W}}$ & $58.43 \mathrm{~kJ} / \mathrm{mol}$ \\
\hline$k_{\text {met }}$ & $2.01 \times 10^{6} \mathrm{~mol} / \mathrm{g} \cdot \mathrm{s} \cdot \mathrm{bar}$ & $K_{\mathrm{W}}$ & $2.76 \times 10^{-2} \mathrm{bar}^{-0.5}$ \\
\hline$E_{\text {met }}$ & $97.39 \mathrm{~kJ} / \mathrm{mol}$ & $k_{\mathrm{o}}$ & $8.79 \times 10^{3} \mathrm{~mol} / \mathrm{g} \cdot \mathrm{s}$ \\
\hline$k_{\mathrm{p}}$ & $1.10 \times 10^{6} \mathrm{~mol} / \mathrm{g} \cdot \mathrm{s} \cdot \mathrm{bar}$ & $E_{\mathrm{o}}$ & $2.77 \times 10^{-5} \mathrm{~mol} / \mathrm{g} \cdot \mathrm{s} \cdot \mathrm{bar}$ \\
\hline$E_{\mathrm{p}}$ & $111.48 \mathrm{~kJ} / \mathrm{mol}$ & $k_{-o}$ & $1.67 \times 10^{-3} \mathrm{bar}^{-1}$ \\
\hline$K_{1}$ & \multicolumn{3}{|c|}{ equilibrium constant of the elementary reaction, 2.64 for F-T synthesis $\left(\mathrm{bar}^{-1}\right)$} \\
\hline$K_{2}$ & \multicolumn{3}{|c|}{ equilibrium constant of the elementary reaction, 2.65 for F-T synthesis $\left(\mathrm{bar}^{-1}\right)$} \\
\hline$K_{3}$ & \multicolumn{3}{|c|}{ equilibrium constant of the elementary reaction, 2.74 for F-T synthesis $\left(\right.$ bar $\left.^{-1}\right)$} \\
\hline$K_{4}$ & \multicolumn{3}{|c|}{ equilibrium constant of the elementary reaction, 2.66 for F-T synthesis $\left(\mathrm{bar}^{-1}\right)$} \\
\hline$K_{5}$ & \multicolumn{3}{|c|}{ equilibrium constant of the elementary reaction, 2.78 for F-T synthesis $\left(\mathrm{bar}^{-1}\right)$} \\
\hline
\end{tabular}

$$
\begin{aligned}
\frac{\mathrm{d} P(n)}{\mathrm{d} t}= & k_{\mathrm{p}} K_{2} K_{5} K_{4} \frac{P_{\mathrm{H}_{2}}{ }^{3} P_{\mathrm{CO}}}{P_{\mathrm{H}_{2} \mathrm{O}}} \prod_{j=2}^{i} \alpha_{j} \\
& {\left[1+\sqrt{K_{2} P_{\mathrm{H}_{2}}}+K_{1} P_{\mathrm{CO}}+K_{3}^{\prime} \frac{P_{\mathrm{H}_{2}}{ }^{2} P_{\mathrm{CO}}}{P_{\mathrm{H}_{2} \mathrm{O}}}\right.} \\
& +K_{1} K_{3} P_{\mathrm{CO}} P_{\mathrm{H}_{2}}+K_{2} K_{5} K_{4} \frac{P_{\mathrm{H}_{2}}{ }^{2.5} P_{\mathrm{CO}}}{P_{\mathrm{H}_{2} \mathrm{O}}} \\
& \left.+K_{4} \frac{P_{\mathrm{H}_{2}}{ }^{2} P_{\mathrm{CO}}}{P_{\mathrm{H}_{2} \mathrm{O}}}\left(1+K_{5} \sqrt{K_{4} P_{\mathrm{H}_{2}}}\right) \sum_{i=2}^{n} \prod_{j=2}^{i}\left(\alpha_{j}\right)\right]^{2} \\
\frac{\mathrm{d} P^{=}(n)}{\mathrm{d} t} & k_{\mathrm{o}}\left(1-\beta_{n}\right) K_{4} \frac{P_{\mathrm{H}_{2}}{ }^{2} P_{\mathrm{CO}}}{P_{\mathrm{H}_{2} \mathrm{O}}} \prod_{j=2}^{i} \alpha_{j} \\
& +11+\sqrt{K_{2} P_{\mathrm{H}_{2}}}+K_{1} P_{\mathrm{CO}}+K_{4} \frac{P_{\mathrm{H}_{2}}{ }^{2} P_{\mathrm{CO}}}{P_{\mathrm{H}_{2} \mathrm{O}}} \\
& +K_{1} K_{3} P_{\mathrm{CO}} P_{\mathrm{H}_{2}}+K_{2} K_{5} K_{4} \frac{P_{\mathrm{H}_{2}}{ }^{2.5} P_{\mathrm{CO}}}{P_{\mathrm{H}_{2} \mathrm{O}}}+K_{4} \frac{P_{\mathrm{H}_{2}}{ }^{2} P_{\mathrm{CO}}}{P_{\mathrm{H}_{2} \mathrm{O}}} \\
& \left.+K_{5} \sqrt{K_{2} P_{\mathrm{H}_{2}}} \sum_{i=2}^{n} \prod_{j=2}^{i}\left(\alpha_{j}\right)\right] \\
&
\end{aligned}
$$

The rates of paraffin and olefin formation with carbon number $n$ are demonstrated in eqs $14-16 .^{7}$ Table 1 summarizes the parameters of the above equations.

\section{MATHEMATICAL MODELING OF A FISCHER-TROPSCH REACTOR}

Since the operating conditions have a significant influence over the product distribution of hydrocarbons and oxygenates, it is quite important to be able to maintain the operating conditions in order to control the selectivity of the product. ${ }^{8-11}$ This section describes the methodology to predict the results of the kinetic model of F-T synthesis and to control the selectivity of the product. In this research, the kinetic modeling was developed with the assumption of no internal and external temperatures or mass transfer gradients in the catalyst.

In particular, the following items were considered for the development of F-T kinetics: (1) the temperature effect on product distribution and (2) the effect of various catalyst sizes. The reaction kinetic parameters were then fitted on the basis of the experimental results obtained under a wide range of operating conditions. Finally, the operating conditions of the reactor were optimized to maximize the F-T products.
Figure 2 illustrates the algorithm of the mathematical modeling of the F-T reactor, and details of the modeling are described in this section.

As illustrated in Figure 2, the feed condition such as temperature, pressure and compositions are initially set. The reactor is divided into a number of sections that are called subPFR in this work, and this number of sub-PFRs is user-defined. As the number of sub-PFRs increases, the more accurate the simulation results that can be obtained. Inside a sub-PFR, liquid and gas dispersion effects were estimated, and the results are applied to the kinetics for the calculation of reaction rates of each reaction mechanism. Then, the heat and mass balance of each sub-PFR is solved by MATLAB solver. This calculation procedure proceeds until the end of the PFR. Finally, the conversion and yields of products are estimated.

3.1. Catalyst Candidates. The three metals known to be most active for $\mathrm{CO}$ hydrogenation to hydrocarbons are $\mathrm{Fe}, \mathrm{Co}$, and $\mathrm{Ru}$. Selection of the optimal material among them is rather complicated because several factors must be considered simultaneously. In general, the cost, availability, desired product spectrum, required catalyst lifetime, and catalyst activity are the main items to consider for the selection of metals. It has been estimated that the entire available world stock of $\mathrm{Ru}$ would be needed to produce enough catalyst for an F-T plant. On the other hand, if it is required for high quality F-T waxes, the $\mathrm{Ru}$ catalyst should be preferred over other catalyst types. Anderson et al. ${ }^{12}$ showed that $0.3 \% \mathrm{Ru}$ on $\mathrm{Al}_{2} \mathrm{O}_{3}$ gave a wax selectivity of $88 \%$, which was considerably higher than the $60 \%$ obtained using an iron-based catalyst under similar conditions. The catalysts can also produce high yields of wax. On the other hand, cobalt can increase the activity of the catalyst, although the price of cobalt catalysts is 10 times more expensive than the equivalent iron-based catalysts. For this reason, a much longer life or higher activity would be required to justify the use of a cobalt catalyst. $^{13}$

In general, the active materials are dispersed on metal oxide supports, and $\mathrm{Ru}, \mathrm{Re}$, or Pt promoters are adopted to prevent catalyst deactivation by carbon formation or oxidation. Compared to iron-based catalysts, Ru-based catalysts tend to produce longer-chained hydrocarbons by readsorption of olefins to the active sites, thus increasing the product selectivity toward heavy hydrocarbons. Iron-based catalysts generally consist of precipitated iron, which is promoted with potassium and copper to obtain a high activity and selectivity. Additionally, in comparison to other metal catalysts, such as cobalt- and ruthenium-based ones, the iron-based catalyst is distinguished by higher conversion and selectivity toward lower olefin 
products. ${ }^{14,15}$ Typically, iron-based catalysts are more sensitive to the water gas shift (WGS) reactions shown in eq 17.

$$
\mathrm{CO}+\mathrm{H}_{2} \mathrm{O}=\mathrm{CO}_{2}+\mathrm{H}_{2}
$$

The WGS reactions become more important as the CO conversion increases. For iron-based catalysts, the pressure generally does not cause a significant impact upon the product distribution.

The effect of particle size on the reaction rate can be quantified using the well-known relation between the effectiveness factor, $\eta$, and the Thiele modulus, $\phi$.

$$
-r_{\mathrm{s}}=\eta k s
$$

The effectiveness factor for the first-order reaction is

$$
\eta=\frac{3}{\phi}\left(\frac{1}{\tanh \phi}-\frac{1}{\phi}\right)
$$

For spherical particles (radius, $P_{\mathrm{r}}$ ) using the first-order kinetics, the Thiele modulus can be expressed as

$$
\phi=\sqrt{\frac{P_{\mathrm{r}}}{3}\left(\frac{k}{D_{\mathrm{e}}}\right)}
$$

where $k$ is the kinetic coefficient $(1 / \mathrm{s})$ and $D_{\mathrm{e}}$ is the effective diffusivity.

The effective diffusivity, $D_{\text {e }}$, appearing in eq 21 , can be determined using the Taylor dispersion (eq 22), in which $D_{\mathrm{e}}$ is related to the Peclet number, $\mathrm{Pe}$. $\mathrm{Pe}$ is determined from the reactor diameter, $d=2 a$, and space velocity, $U_{\mathrm{G}}$.

$$
D_{\mathrm{e}}=D\left(1+\frac{1}{192} P e^{2}\right)
$$

where $P e=\mathrm{d}_{\mathrm{G}} / D$ is the Peclet number.
The effect of the Taylor dispersion is therefore more pronounced at higher Peclet numbers and reactor diameters. The diffusivity in eq 21 is defined as

$$
D=\frac{R T}{6 \pi \mu P_{\mathrm{r}}}
$$

where $\mu, R$, and $T$ are the solution viscosity, gas constant $(8.314 \mathrm{~kJ} / \mathrm{mol})$, and temperature, respectively. The Thiele modulus (eq 20) is dependent upon the particle radius of the catalyst, the diffusivity coefficient, and the rate constant. The Thiele modulus is defined as a function of the effectiveness factor, $\eta$, from eq 19. As shown in eqs 20-22, the effect of the catalyst particle size can be estimated using the effectiveness factor.

It is assumed that the primary reaction takes place on the separated catalyst sites $(\theta)$, whereas the secondary reactions take place on the catalyst site $(\sigma)$. To consider the effect of catalyst active sites, the kinetic models were modified by introducing a parameter. Equations 10, 11, and 12 of the two-phase model can be respectively rewritten in the following forms

$$
\begin{aligned}
R_{\mathrm{CH}_{4}, \mathrm{C}}= & k_{\mathrm{met}} \frac{\mathrm{SA}_{\mathrm{E} 1}^{\prime}}{\mathrm{SA}_{1}^{\prime}} K_{1} K_{5} K_{4} \frac{P_{\mathrm{H}_{2}}{ }^{3} P_{\mathrm{CO}}}{P_{\mathrm{H}_{2} \mathrm{O}}} \\
& / 1+\sqrt{K_{2} P_{\mathrm{H}_{2}}}+K_{1} P_{\mathrm{CO}}+K_{4} \frac{P_{\mathrm{H}_{2}}{ }^{2} P_{\mathrm{CO}}}{P_{\mathrm{H}_{2} \mathrm{O}}} \\
& +K_{1} K_{3} P_{\mathrm{CO}} P_{\mathrm{H}_{2}}+K_{5} K_{4} K_{4}{ }^{0.5} \frac{P_{\mathrm{H}_{2}}{ }^{2.5} P_{\mathrm{CO}}}{P_{\mathrm{H}_{2} \mathrm{O}}} \\
& \left.+K_{4} \frac{P_{\mathrm{H}_{2}}{ }^{2} P_{\mathrm{CO}}}{P_{\mathrm{H}_{2} \mathrm{O}}}\left(1+K_{5} \sqrt{K_{2} P_{\mathrm{H}_{2}}}\right) \sum_{i=2}^{n} \prod_{j=2}^{i}\left(\alpha_{j}\right)\right]^{2}
\end{aligned}
$$

$$
\begin{aligned}
& R_{\mathrm{C}_{n} \mathrm{H}_{2 n+2}, \mathrm{C}}=k_{\mathrm{P}} \frac{\mathrm{SA}_{\mathrm{E} 2}^{\prime}}{\mathrm{SA}_{2}^{\prime}} K_{2} K_{5} K_{4} \frac{P_{\mathrm{H}_{2}}{ }^{2} P_{\mathrm{CO}}}{P_{\mathrm{H}_{2} \mathrm{O}}} \prod_{j=2}^{i} \alpha_{j} \\
& \quad / 1+\sqrt{K_{2} P_{\mathrm{H}_{2}}}+K_{1} P_{\mathrm{CO}}+K_{4} \frac{P_{\mathrm{H}_{2}}{ }^{2} P_{\mathrm{CO}}}{P_{\mathrm{H}_{2} \mathrm{O}}}+K_{1} K_{3} P_{\mathrm{CO}} P_{\mathrm{H}_{2}}+K_{5} K_{4} K_{2} \cdot \frac{\left.0.5 \frac{P_{\mathrm{H}_{2}}{ }^{2.5} P_{\mathrm{CO}}}{P_{\mathrm{H}_{2} \mathrm{O}}}+K_{4} \frac{P_{\mathrm{H}_{2}}{ }^{2} P_{\mathrm{CO}}}{P_{\mathrm{H}_{2} \mathrm{O}}}\left(1+K_{5} \sqrt{K_{2} P_{\mathrm{H}_{2}}}\right) \sum_{i=2}^{n} \prod_{j=2}^{i}\left(\alpha_{j}\right)\right]^{2}}{}
\end{aligned}
$$

$$
\begin{aligned}
R_{\mathrm{C}_{n} \mathrm{H}_{2 n, \mathrm{C}}}= & k_{\mathrm{o}} \frac{\mathrm{SA}_{\mathrm{E} 3}^{\prime}}{\mathrm{SA}_{3}^{\prime}}\left(1-\beta_{n}\right) K_{4} \frac{P_{\mathrm{H}_{2}}{ }^{2} P_{\mathrm{CO}}}{P_{\mathrm{H}_{2} \mathrm{O}}} \prod_{j=2}^{i} \alpha_{j} \\
& / 1+\sqrt{K_{2} P_{\mathrm{H}_{2}}}+K_{1} P_{\mathrm{CO}}+K_{4} \frac{P_{\mathrm{H}_{2}}{ }^{2} P_{\mathrm{CO}}}{P_{\mathrm{H}_{2} \mathrm{O}}} \\
& +K_{1} K_{4} P_{\mathrm{CO}} P_{\mathrm{H}_{2}}+K_{5} K_{4} K_{2}{ }^{0.5} \frac{P_{\mathrm{H}_{2}}{ }^{2.5} P_{\mathrm{CO}}}{P_{\mathrm{H}_{2} \mathrm{O}}} \\
& \left.+K_{4} \frac{P_{\mathrm{H}_{2}}{ }^{2} P_{\mathrm{CO}}}{P_{\mathrm{H}_{2} \mathrm{O}}}\left(1+K_{5} \sqrt{K_{2} P_{\mathrm{H}_{2}}}\right) \sum_{i=2}^{n} \prod_{j=2}^{i}\left(\alpha_{j}\right)\right]
\end{aligned}
$$

where $\mathrm{SA}_{1}^{\prime}, \mathrm{SA}_{2}^{\prime}$ and $\mathrm{SA}_{3}^{\prime}$ are catalyst active surface areas of active site $\theta$ for the model and $\mathrm{SA}_{\mathrm{E} 1}^{\prime}, \mathrm{SA}_{\mathrm{E} 2}^{\prime}$, and $\mathrm{SA}_{\mathrm{E} 3}^{\prime}$ are catalyst active surface areas of active sites $\theta$ and $\sigma$ for experimental data.
3.2. Choice of Reactor. Many researchers have studied reactor modeling of fixed bed and slurry bed reactors for F-T reactions under various operating conditions. In addition, various aspects, such as temperature control strategy and catalyst loading, have been studied in order to achieve higher conversion of raw materials and reduction of capital costs. The following sections illustrate how the important parameters in the kinetics models were estimated in this research.

3.2.1. Liquid-Phase Dispersion Coefficient. Various literature correlations for liquid-phase dispersion in a bubble column were summarized by Wendt et al. ${ }^{16}$ The correlation proposed by Deckwer et al. ${ }^{17}$ provides a good estimate of the liquid-phase dispersion coefficient.

$$
\begin{aligned}
& D_{\mathrm{L}}=0.68 D_{\mathrm{r}}^{1.4} U_{\mathrm{G}}^{0.33} \\
& U_{\mathrm{G}}=\frac{V_{0}}{\pi D_{\mathrm{r}}^{2}}
\end{aligned}
$$

where, $D_{\mathrm{r}}, U_{\mathrm{G}}$, and $V_{0}$ are reactor diameter $(\mathrm{m})$, gas superficial velocity $(\mathrm{m} / \mathrm{s})$, and total flow rate $\left(\mathrm{m}^{3} / \mathrm{s}\right)$, respectively. 


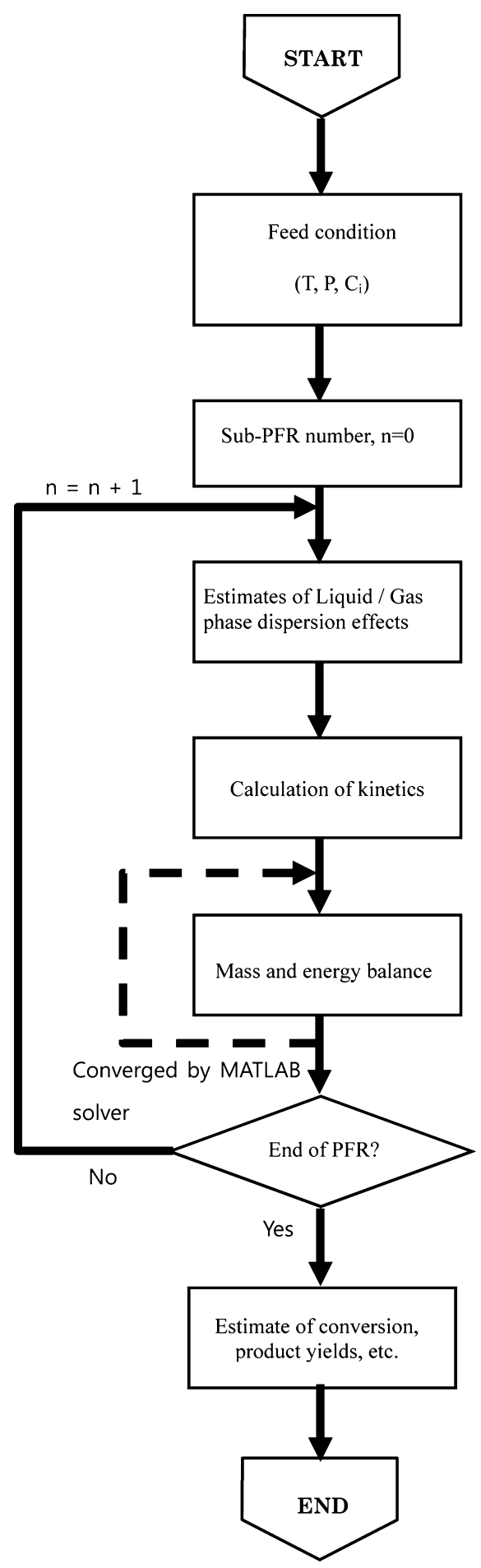

Figure 2. Mathematical modeling algorithm of a F-T reactor.

3.2.2. Gas-Phase Dispersion Coefficient. Only a few studies have investigated gas-phase dispersion in bubble columns. ${ }^{18-20}$ Kawagoe $^{20}$ observed that the correlation of Towell and Ackerman ${ }^{18}$ provided a good estimate of the overall gas-phase dispersion coefficient in bubble columns.

$$
D_{\mathrm{G}}=20 D_{\mathrm{r}}^{2} U_{\mathrm{G}}
$$

3.2.3. Effective Dispersion Coefficient. The relationship between liquid- and gas-phase dispersion coefficients can be described by the effective dispersion coefficient $\left(D_{\mathrm{E}}\right)$ using the following equation:

$$
D_{\mathrm{E}}=\frac{D_{\mathrm{G}}+\frac{C_{\mathrm{L}}}{H C_{\mathrm{G}}} D_{\mathrm{L}}}{1+\frac{C_{\mathrm{L}}}{H C_{\mathrm{G}}}}
$$

Assuming that mass transfer resistance is small, $C_{\mathrm{G}}=H C_{\mathrm{L}}$ at every point. Therefore, eq 29 can be simplified to

$$
D_{\mathrm{E}}=\frac{D_{\mathrm{G}}+\frac{D_{\mathrm{L}}}{H^{2}}}{1+\frac{1}{H^{2}}}
$$

where $H$ is Henry's constant.

In this work, the effectiveness factor was incorporated into the modified methane, paraffin, and olefin formation equations (eqs 23-25) to consider the impact of catalyst particle size and diffusivity of reactants on the overall reactions. The resulting equations are as follows:

$$
\begin{aligned}
R_{\mathrm{CH}_{4}, \mathrm{C}}= & \eta\left\{k_{\mathrm{met}} \frac{\mathrm{SA}_{\mathrm{E} 1}^{\prime}}{\mathrm{SA}_{1}^{\prime}} K_{1} K_{5} K_{4} \frac{P_{\mathrm{H}_{2}}{ }^{3} P_{\mathrm{CO}}}{P_{\mathrm{H}_{2} \mathrm{O}}}\right. \\
& / 1+\sqrt{K_{2} P_{\mathrm{H}_{2}}}+K_{1} P_{\mathrm{CO}}+K_{4} \frac{P_{\mathrm{H}_{2}}{ }^{2} P_{\mathrm{CO}}}{P_{\mathrm{H}_{2} \mathrm{O}}} \\
& +K_{1} K_{3} P_{\mathrm{CO}} P_{\mathrm{H}_{2}}+K_{5} K_{4} K_{4}{ }^{0.5} \frac{P_{\mathrm{H}_{2}}{ }^{2.5} P_{\mathrm{CO}}}{P_{\mathrm{H}_{2} \mathrm{O}}} \\
& \left.\left.+K_{4} \frac{P_{\mathrm{H}_{2}}{ }^{2} P_{\mathrm{CO}}}{P_{\mathrm{H}_{2} \mathrm{O}}}\left(1+K_{5} \sqrt{K_{2} P_{\mathrm{H}_{2}}}\right) \sum_{i=2}^{n} \prod_{j=2}^{i}\left(\alpha_{\mathrm{j}}\right)\right]^{2}\right\}
\end{aligned}
$$

$$
\begin{aligned}
R_{\mathrm{C}_{n} \mathrm{H}_{2 n+2} \mathrm{C}}= & \eta\left\{k_{\mathrm{p}} \frac{\mathrm{SA}_{\mathrm{E} 2}^{\prime}}{\mathrm{SA}_{2}^{\prime}} K_{2} K_{5} K_{4} \frac{P_{\mathrm{H}_{2}}{ }^{2} P_{\mathrm{CO}}}{P_{\mathrm{H}_{2} \mathrm{O}}} \prod_{j=2}^{i} \alpha_{j}\right. \\
& / 1+\sqrt{K_{2} P_{\mathrm{H}_{2}}}+K_{1} P_{\mathrm{CO}}+K_{4} \frac{P_{\mathrm{H}_{2}}{ }^{2} P_{\mathrm{CO}}}{P_{\mathrm{H}_{2} \mathrm{O}}} \\
& +K_{1} K_{3} P_{\mathrm{CO}} P_{\mathrm{H}_{2}}+K_{5} K_{4} K_{2}{ }^{0.5} \frac{P_{\mathrm{H}_{2}}{ }^{2.5} P_{\mathrm{CO}}}{P_{\mathrm{H}_{2} \mathrm{O}}} \\
& \left.\left.+K_{4} \frac{P_{\mathrm{H}_{2}}{ }^{2} P_{\mathrm{CO}}}{P_{\mathrm{H}_{2} \mathrm{O}}}\left(1+K_{5} \sqrt{K_{2} P_{\mathrm{H}_{2}}}\right) \sum_{i=2}^{n} \prod_{j=2}^{i}\left(\alpha_{\mathrm{j}}\right)\right]^{2}\right\}
\end{aligned}
$$

$$
\begin{aligned}
R_{\mathrm{C}_{n} \mathrm{H}_{2 n, \mathrm{C}}}= & \eta\left\{k_{\mathrm{o}} \frac{\mathrm{SA}_{\mathrm{E} 3}^{\prime}}{\mathrm{SA}_{3}^{\prime}}\left(1-\beta_{n}\right) K_{4} \frac{P_{\mathrm{H}_{2}}{ }^{2} P_{\mathrm{CO}}}{P_{\mathrm{H}_{2} \mathrm{O}}} \prod_{j=2}^{i} \alpha_{j}\right. \\
& / 1+\sqrt{K_{2} P_{\mathrm{H}_{2}}}+K_{1} P_{\mathrm{CO}}+K_{2} \frac{P_{\mathrm{H}_{2}}{ }^{2} P_{\mathrm{CO}}}{P_{\mathrm{H}_{2} \mathrm{O}}} \\
& +K_{1} K_{2} P_{\mathrm{CO}} P_{\mathrm{H}_{2}}+K_{5} K_{4} K_{2}{ }^{0.5} \frac{P_{\mathrm{H}_{2}}{ }^{2.5} P_{\mathrm{CO}}}{P_{\mathrm{H}_{2} \mathrm{O}}} \\
& \left.\left.+K_{4} \frac{P_{\mathrm{H}_{2}}{ }^{2} P_{\mathrm{CO}}}{P_{\mathrm{H}_{2} \mathrm{O}}}\left(1+K_{5} \sqrt{K_{2} P_{\mathrm{H}_{2}}}\right) \sum_{i=2}^{n} \prod_{j=2}^{i}\left(\alpha_{n}\right)\right]\right\}
\end{aligned}
$$


Table 2. Reaction Conditions of Experimental Data Employed for Base Case Model and Parameter Fitting

\begin{tabular}{|c|c|c|c|c|c|c|}
\hline & \multicolumn{2}{|c|}{ Yang } & \multirow[b]{2}{*}{$\mathrm{Ji}$} & \multirow[b]{2}{*}{$\mathrm{Ma}$} & \multirow[b]{2}{*}{ Pour } & \multirow[b]{2}{*}{ Bukur } \\
\hline & dataset a & dataset $b$ & & & & \\
\hline temp $(\mathrm{K})$ & 556 & 585 & 573 & 553 & 563 & 523 \\
\hline pressure $(\mathrm{MPa})$ & 2.51 & 3.02 & 2.25 & 2.01 & 1.7 & 1.48 \\
\hline $\mathrm{H}_{2} / \mathrm{CO}$ feed ratio & 2.62 & 2.04 & 1.97 & 0.9 & 1.0 & 0.67 \\
\hline space velocity $(\mathrm{m} / \mathrm{kg}$ cat. $\mathrm{h})$ & $1.6 \times 10^{-3}$ & $3.2 \times 10^{-3}$ & 7 & 3 & 13.28 & 3 \\
\hline iron-based catalyst & $\mathrm{Fe}-\mathrm{Mn}$ & $\mathrm{Fe}-\mathrm{Mn}$ & $\mathrm{Fe}-\mathrm{Mn}$ & $\mathrm{Fe}-\mathrm{Cu}-\mathrm{M}-\mathrm{K} / \mathrm{AC}$ & $\mathrm{Fe}-\mathrm{Cu}$ & $\mathrm{Fe}-\mathrm{Cu}-\mathrm{K}-\mathrm{SiO}_{2}$ \\
\hline diameter $(\mathrm{m})$ & $\approx 3 \times 10^{-4}$ & $\approx 3 \times 10^{-4}$ & $\approx 2.75 \times 10^{-4}$ & $\approx 5.95 \times 10^{-4}$ & $\approx 2.75 \times 10^{-4}$ & $\approx 3.75 \times 10^{-4}$ \\
\hline reactor & fixed-bed & fixed-bed & fixed-bed & fixed-bed & fixed-bed & fixed-bed \\
\hline diameter $(\mathrm{m})$ & 0.012 & 0.012 & 0.014 & 0.008 & 0.005 & 0.01 \\
\hline
\end{tabular}

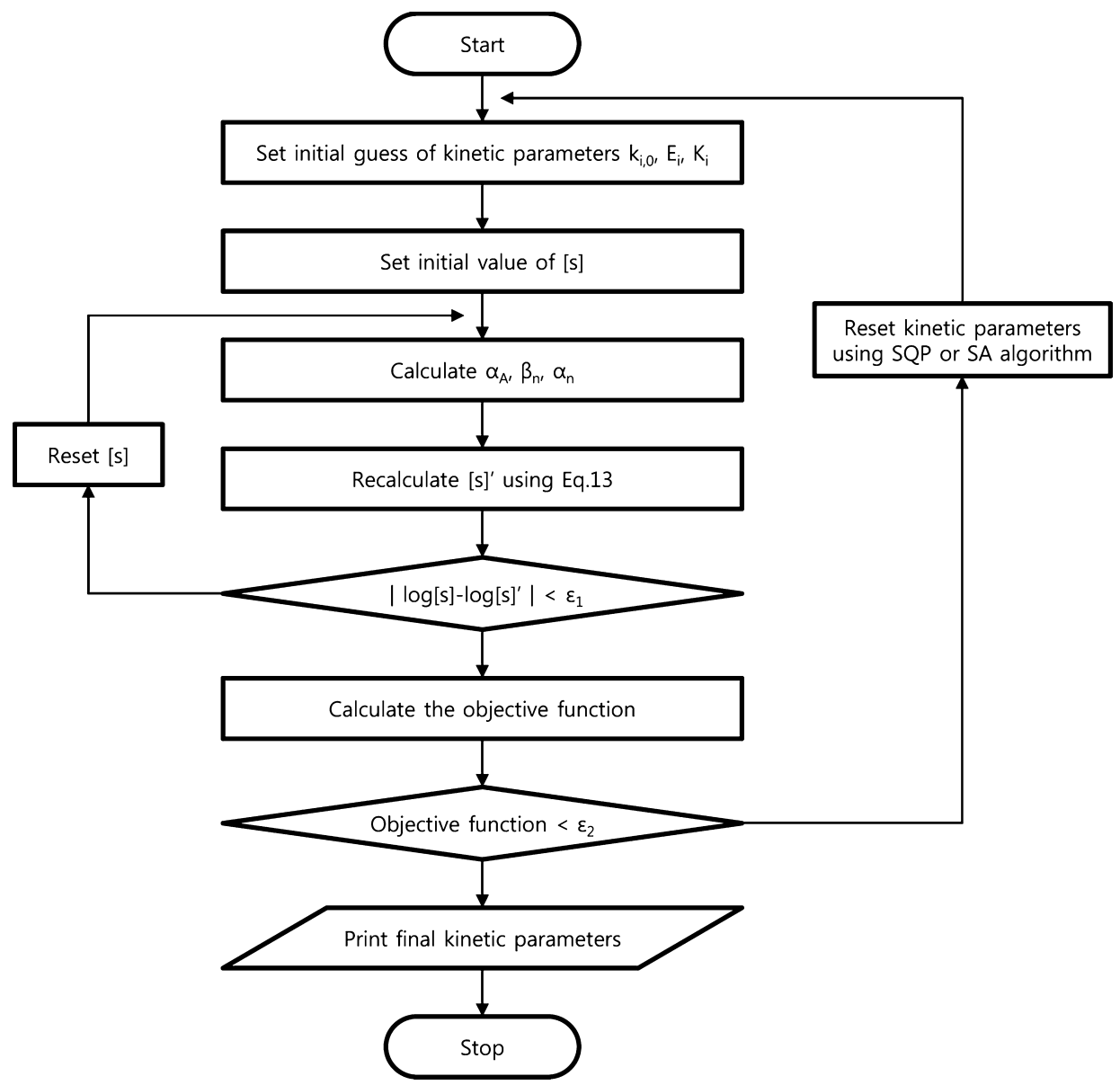

Figure 3. Schematic diagram of the algorithm for kinetic parameter estimation.

In eq 33 , the readsorption term is $k_{0}\left(\mathrm{SA}_{\mathrm{E} 3}^{\prime} / \mathrm{SA}_{3}^{\prime}\right)\left(1-\beta_{n}\right)$, where $\beta_{n}$ can be estimated from eq 12 . For the modeling of reaction systems, various design variables, such as the modified kinetics, liquid- and gas-phase dispersion coefficients, and residence time of the main fluids inside a reactor, were incorporated into the model. Mass and heat balances were then solved using the MATLAB program. The kinetic model was named as the base case model. Figure 2 shows the modeling algorithm of an F-T reactor.

Iron-based catalysts in F-T synthesis form mostly straight chain hydrocarbons. These products $(\mathrm{C} 5-\mathrm{C} 20)$ are sold to the market as gasoline or diesel. By controlling the reaction conditions, such as temperature, pressure, and $\mathrm{H}_{2} / \mathrm{CO}$ ratio in the feed stream, byproducts such as heavy wax and methane products can be minimized. Therefore, the reaction conditions in the F-T process are quite important, since they determine the hydrocarbon distribution of both paraffins and olefins.

The base case model was developed on the basis of the data from Yang ${ }^{6}$ by considering parameters such as temperature, catalyst size, reactor size, and residence time, as shown in eqs $31-33$. After the base case model was developed, the parameters of eqs 31-33 were fitted to multiple sets of experimental data to enhance the accuracy of the modeling. The sets of experimental data were taken from other previous research established by Ji et al., ${ }^{21}$ Ma et al., ${ }^{11}$ Pour et al., ${ }^{22}$ and Bukur et al. ${ }^{23}$ Table 2 shows the reaction conditions of the experimental data from the above authors.

Data fitting of the optimized F-T model was carried out using the method of least-squares, which minimizes the sum of squared residuals, the difference between an observed value and the fitted 


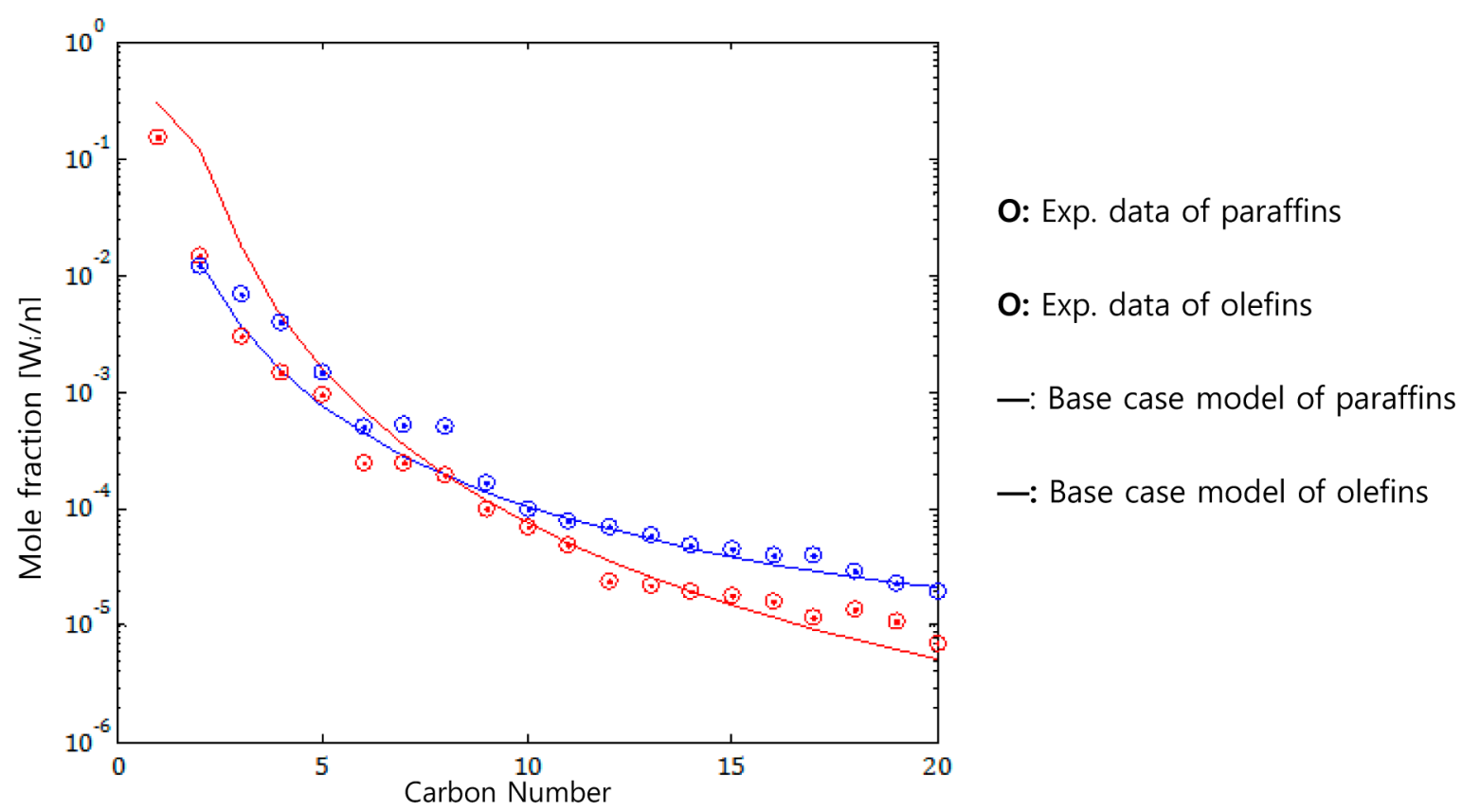

Figure 4. Comparison of the base case model with the experimental data (dataset a, Table 2) from Yang. ${ }^{6}$

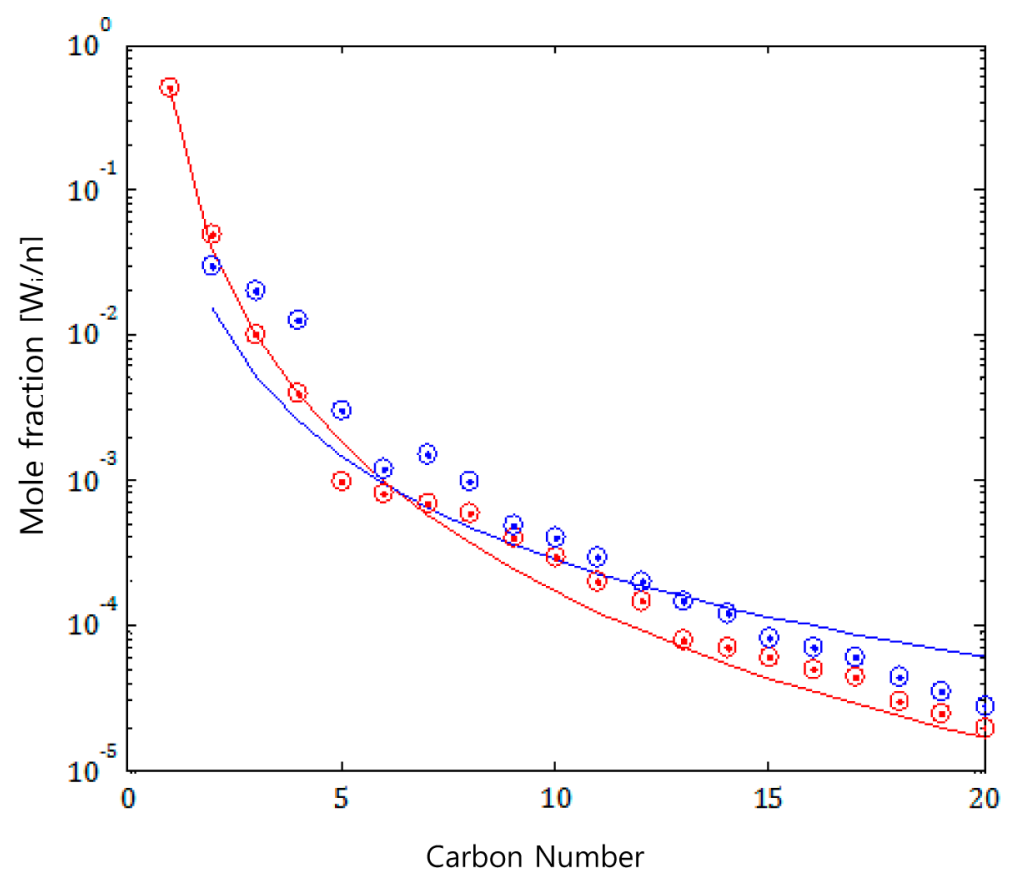

O: Exp. data of paraffins

O: Exp. data of olefins

-: Base case model of paraffins

—: Base case model of olefins

Figure 5. Comparison of the base case model with the experimental data (dataset b, Table 2) from Yang. ${ }^{6}$

value provided by the model. The least-squares estimate of the model is given by

$$
\text { error }=\sum_{i}[\operatorname{expl} \text { data }(i)-\text { base case model data }(i)]^{2}
$$

For the optimization, eq 34 was used as an objective function, while reaction kinetic constants and active site parameters were considered as optimization variables. A detailed description about these variables is illustrated in section 4 .

For the optimization of a nonlinear least-squares problem involving experimental data, the SQP (successive quadratic programming) algorithm is widely used method due to its relatively stable and rapid convergence. However, in most cases, nonlinear least-squares problems have objective functions with multiple local minima. In cases with multiple minima, the algorithm converges to the global minimum only if the initial guess is already somewhat close to the final solution. For this reason, in this work, in order to avoid getting trapped in local minima, first the parameters of the model were estimated by using a stochastic optimization algorithm such as simulated annealing (SA) as a means of global optimization, and then those were subsequently fine-tuned by the SQP algorithm. The detailed algorithm for the parameter estimation with this hybrid optimization method is shown in Figure 3.

In addition, the production of alcohols and acids is also calculated by the optimized F-T model. 
Table 3. Reaction Rate Constants and Active Site Parameters of Each Set of Experimental Data

$$
\begin{aligned}
& \text { Ji et al. }{ }^{21} \\
& k_{\mathrm{CG}_{\mathrm{Ji}}}=k_{\mathrm{CG} \sigma 1} A_{\mathrm{CG} \sigma 1_{\mathrm{Ji}}} \\
& k_{\text {met } \mathrm{Ji}_{\mathrm{i}}}=k_{\text {met } \sigma 1} A_{\text {met } \sigma 1_{\mathrm{Ji}}} \\
& k_{\mathrm{p}_{\mathrm{ji}}}=k_{\mathrm{p} \sigma 1} A_{\mathrm{p} \sigma 1_{\mathrm{ji}}} \\
& k_{\mathrm{oji}_{\mathrm{i}}}=k_{\sigma \sigma 1} A_{\mathrm{o} \sigma 1 \mathrm{~J}_{\mathrm{ji}}} \\
& k_{-\mathrm{oj}_{\mathrm{i}}}=k_{-\mathrm{o} \sigma \mathrm{1}} A_{-\mathrm{o} \sigma 11_{\mathrm{ji}}} \\
& \text { Ma et al. }{ }^{11} \quad k_{\mathrm{CG}_{\mathrm{Ma}}}=k_{\mathrm{CG} \sigma 1} A_{\mathrm{CG} \sigma 1_{\mathrm{Ma}}} \\
& k_{\mathrm{met}_{\mathrm{Ma}}}=k_{\mathrm{met} \sigma 1} A_{\mathrm{met} \sigma 1_{\mathrm{Ma}}} \\
& k_{\mathrm{p}_{\mathrm{Ma}}}=k_{\mathrm{p} \sigma 1} A_{\mathrm{p} \sigma 1_{\mathrm{Ma}}} \\
& k_{\mathrm{o}}=k_{\mathrm{o} \sigma 1} A_{\mathrm{o} \sigma 1_{\mathrm{Ma}}} \\
& k_{-\mathrm{o}_{\mathrm{Ma}}}=k_{-\mathrm{o} \sigma 1} A_{-\mathrm{o} \sigma 1_{\mathrm{Ma}}} \\
& \text { Pour et al. }{ }^{22} \quad k_{\mathrm{CG}_{\text {Pour }}}=k_{\mathrm{CG} \sigma 1} A_{\mathrm{CG} \sigma 1_{\text {Pour }}} \\
& k_{\text {met }_{\text {pour }}}=k_{\text {met } \sigma 1} A_{\text {met } \sigma 1_{\text {pour }}} \\
& k_{\mathrm{P}_{\text {Pour }}}=k_{\mathrm{p} \sigma 1} A_{\mathrm{p} \sigma 1_{\mathrm{Pour}}} \\
& k_{\mathrm{o}_{\text {Pour }}}=k_{\mathrm{o} \sigma 1} A_{\mathrm{o} \sigma 1_{\text {Pour }}} \\
& k_{-o_{\text {Pour }}}=k_{-o \sigma 1} A_{-o \sigma 1_{\text {Pour }}} \\
& \text { Bukur et al. }{ }^{23} \\
& k_{\mathrm{CG}_{\text {Bukur }}}=k_{\mathrm{CG} \sigma 1} A_{\mathrm{CG} \sigma 1_{\text {Bukur }}} \\
& k_{\text {met Bukur }_{\text {Bur }}}=k_{\text {meto1 } 1} A_{\text {met } \sigma 1_{\text {Bukur }}} \\
& k_{\mathrm{p}_{\text {Bukur }}}=k_{\mathrm{p} \sigma 1} A_{\mathrm{p} \sigma 1_{\text {Bukur }}} \\
& k_{\mathrm{o}_{\text {Bukur }}}=k_{\mathrm{o} \sigma \mathrm{1}} A_{\mathrm{o} \sigma 1_{\text {Bukur }}} \\
& k_{-\mathrm{o}_{\text {Bukur }}}=k_{-\mathrm{o} \sigma 1} A_{-\mathrm{o} \sigma 1_{\text {Bukur }}}
\end{aligned}
$$

Finally, F-T reactor performance was analyzed using MATLAB software, in order to determine the optimum reactor operating conditions required to maximize the production of transportation fuels, such as gasoline and diesel.

\section{RESULTS}

The base case model was developed in the form of a two-phase reactor, based on the model that Yang developed in 2004. The effectiveness factor was then incorporated into the model to consider the diffusivity of the reactants and products, as well as the size of the catalyst. Finally, for the validation of the model, the simulation results were compared with experimental works established by Yang. ${ }^{6}$

Figures 4 and 5 compare experimental data from Yang's work, and the estimated product distributions from the model under various reactor operating temperatures. These figures illustrate that the product distributions of hydrocarbon products from the

\begin{tabular}{|c|c|c|c|c|c|c|c|}
\hline & \multicolumn{2}{|c|}{ kinetic parameters } & & \multicolumn{4}{|c|}{ active sites values } \\
\hline & original model & modified model & & $\mathrm{Ji}$ & $\mathrm{Ma}$ & Pour & Bukur \\
\hline$k_{\mathrm{CG}}$ & $2.84 \times 10^{9}$ & $3.49 \times 10^{8}$ & $A_{\mathrm{CG} \sigma 1}$ & 0.167 & $1.8 \times 10^{-5}$ & $8.7 \times 10^{-6}$ & 14.65 \\
\hline$k_{\text {met }}$ & $7.24 \times 10^{11}$ & $1.02 \times 10^{14}$ & $A_{\operatorname{met} \sigma 1}$ & 0.00057 & 0.0003 & $1.07 \times 10^{-6}$ & 0.0863 \\
\hline$k_{\mathrm{p}}$ & $3.6 \times 10^{11}$ & $3.36 \times 10^{13}$ & $A_{\mathrm{p} \sigma 1}$ & 0.0063 & $3.5 \times 10^{-5}$ & 0.004 & 0.8112 \\
\hline$k_{\mathrm{o}}$ & $3.16 \times 10^{9}$ & $3.19 \times 10^{10}$ & $A_{\mathrm{o} \sigma 1}$ & $8.4 \times 10^{-5}$ & $3.3 \times 10^{-9}$ & $2.3 \times 10^{-10}$ & $1.37 \times 10^{-8}$ \\
\hline \multirow[t]{2}{*}{$k_{-o}$} & 9.972 & $3.9 \times 10^{3}$ & $A_{-\mathrm{o} \sigma \mathrm{l}}$ & 0.013 & $6.2 \times 10^{-6}$ & 9.17 & 0.04498 \\
\hline & & & error & 6.79 & 34 & 21.25 & 0.53 \\
\hline
\end{tabular}
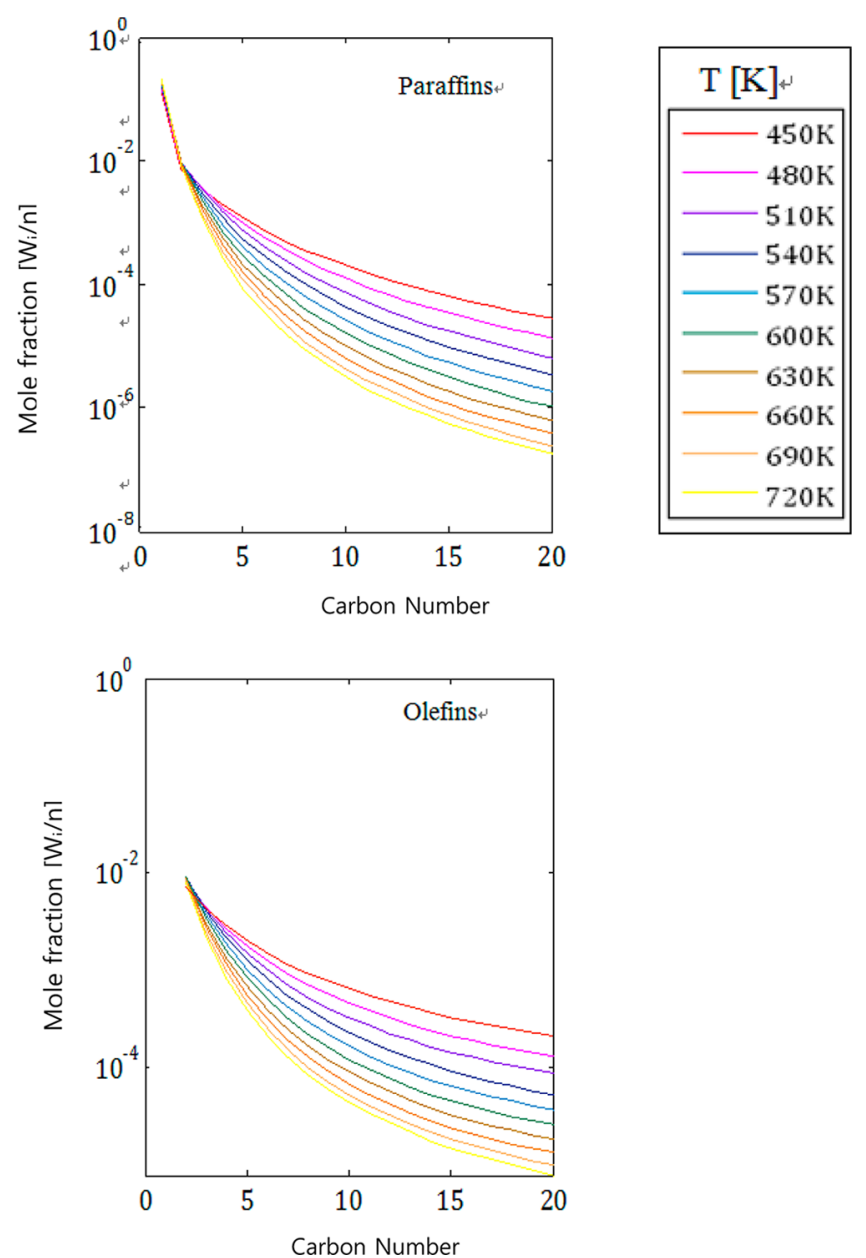

Figure 6. Temperature effect on carbon number distributions.

model are in agreement with the experimental results, and the deviation for methane seems to be relatively small.

The base case model appears to provide relatively good agreement with the experimental data overall, although small deviations exist for the olefin product distribution in $\mathrm{C} 1-\mathrm{C} 4$ and C16+ products.

In order to investigate relative catalytic effect of catalysts for each experimental data, the active site parameter was introduced as an indicator of the relative activity. The rate equation for catalysts that have one type of active site should be expressed as eq 35 , which defines the rate constants $k_{\sigma 1}$ and active site parameter $A_{\sigma 1}$ of $\sigma$ active site on the catalyst.

$$
r=k_{\sigma 1} A_{\sigma 1}\left[\mathrm{C}_{\text {hydrocarbon }}\right]
$$

It is assumed that the active site on the catalyst is only one type, $\sigma 1$, and fundamental rate constants $k_{\mathrm{CG} \sigma 1}, k_{\mathrm{met} \sigma 1}, k_{\mathrm{p} \sigma 1}$, and $k_{-\mathrm{o} \sigma 1}$

Table 4. Kinetic Parameters of Original and Modified Models and Active Site Values after Optimization 

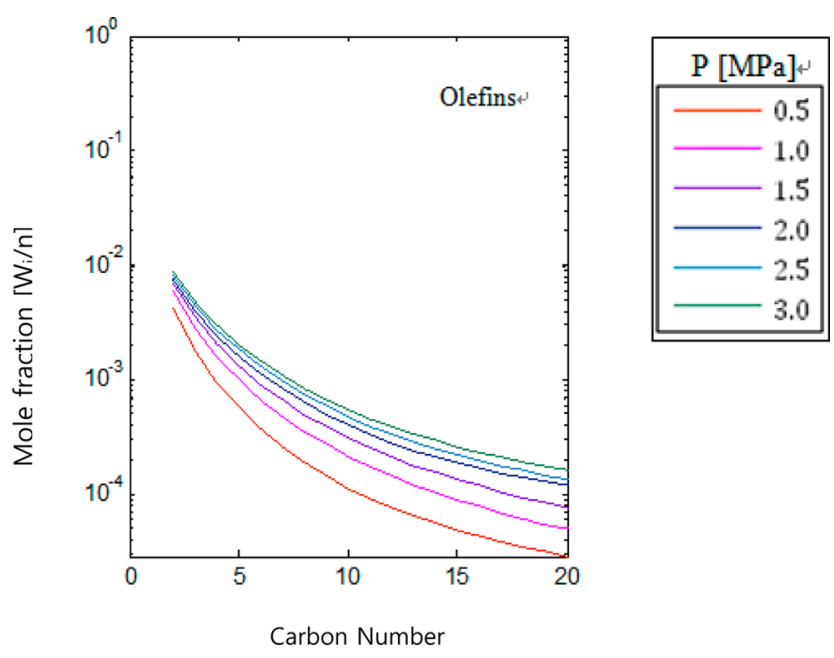

is lower than that of olefins at high temperature. This agrees with the correlation between temperature and olefin selectivity that Gerad $^{24}$ suggested in 1999.

Chain length distributions are shown in Figure 6 under different pressures, ranging from 0.5 to $3 \mathrm{MPa}$. Figure 7 indicates that the carbon number distribution of products is much less sensitive to reaction pressure than temperature. Furthermore, low pressure leads to higher amounts of light paraffins and lower amounts of olefins. For example, the selectivity of $\mathrm{C5}+$ in the pressure range from 0.5 to $0.9 \mathrm{MPa}$ is lower than that in the pressure range from 1.0 to $1.5 \mathrm{MPa}$, as shown in Figure 7 . According to the results, low pressure $(0.5-0.9 \mathrm{MPa})$ leads to higher amounts of light paraffins $(\mathrm{C} 1-\mathrm{C} 3)$ and less heavy paraffins and olefins (C4-C20). These results are in agreement with the results of Pour et al. ${ }^{22}$ and Mirzaei et al. ${ }^{25}$

Figure 8 shows how the ratio of $\mathrm{H}_{2} / \mathrm{CO}$ in the feed stream affects the chain length distribution of the hydrocarbon products

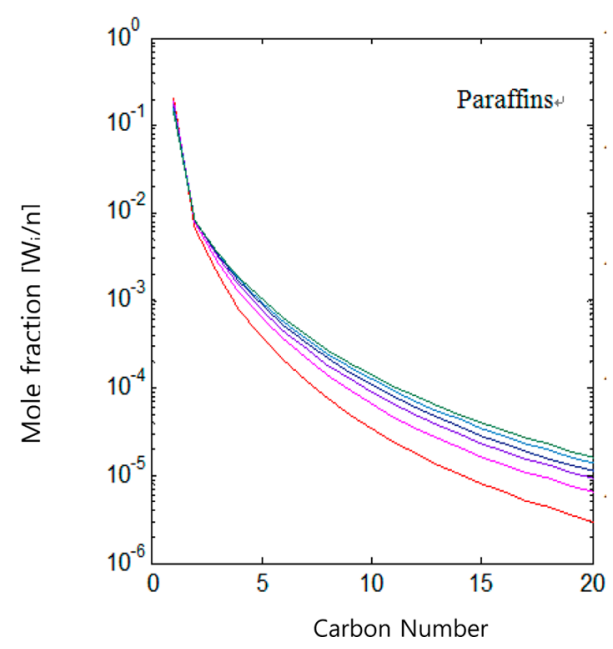

Figure 7. Pressure effect on carbon number distributions.

on the catalyst are the same for all the researchers. Equations that show the relation between rate constants and active site parameters for four individual modified models are listed in Table 3 . The active site parameters calculated by the equations are shown in Table 4.

As indicated in Table 4, for the industrial $\mathrm{Fe}-\mathrm{Mn}$ catalyst from Ji, chain growth and olefin readsorption reactions were more active than other reactions in the acitve site, while data from $\mathrm{Ma}$ showed generally low activity for the whole reaction. In addition, from Pour's data, the formation of paraffins and the olefin readsorption reaction were considerably more active than other formation reactions. The active site parameters for chain growth from Bukur's data showed the highest value of 14.65, which means that this catalyst is suitable for producing hydrocarbons with high carbon number.

The paraffin and olefin distributions under the temperature range of $450-720 \mathrm{~K}$ are analyzed in Figure 6. This figure shows that high temperatures lead to a greater decrease in heavy paraffin and olefin products compared with light hydrocarbons. Higher temperatures lead to higher amounts of light paraffin and lower amounts of heavy paraffin. These results are in agreement with the results of Ji et al. ${ }^{21}$ On the basis of these results, it is concluded that low temperature is preferable for the increased production of heavy olefins, whereas high temperature is preferable for the increased production of light olefins. It is also interesting to mention that the production of paraffins
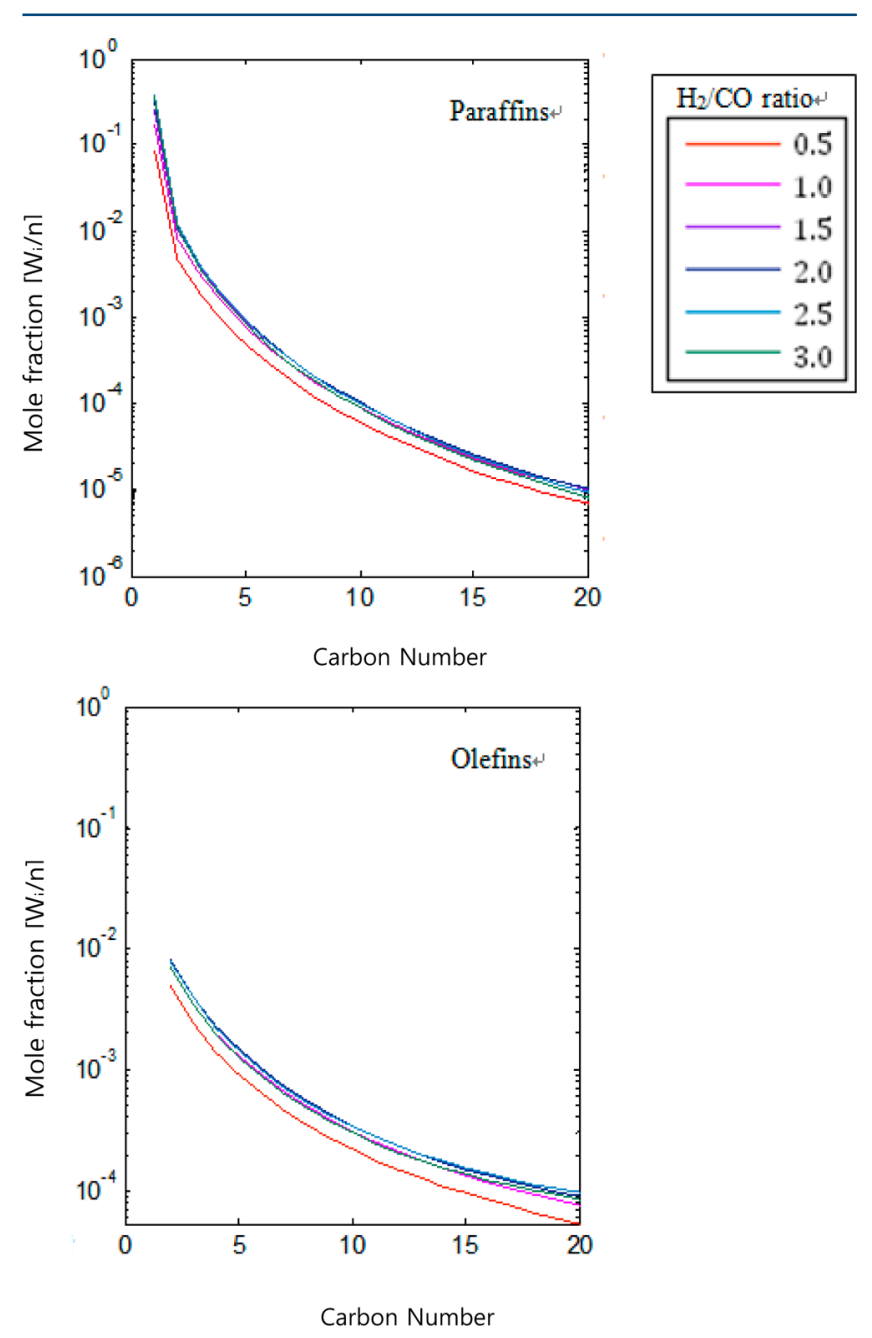

Figure 8. Effect of $\mathrm{H}_{2} / \mathrm{CO}$ feed ratio on carbon number distributions.

when an iron catalyst is used at a temperature of $510 \mathrm{~K}$ and a pressure of 1.0 MPa. The results show that a high $\mathrm{H}_{2} / \mathrm{CO}$ feed ratio is preferable for increased production of hydrocarbons, but its impact is less significant than temperature, as shown in Figures 6 and 8.

Figure 9 shows the influence of space velocity on the paraffin and olefin distributions. Hydrocarbon products have a small change when space velocities are larger than 0.3 . However, a higher space 


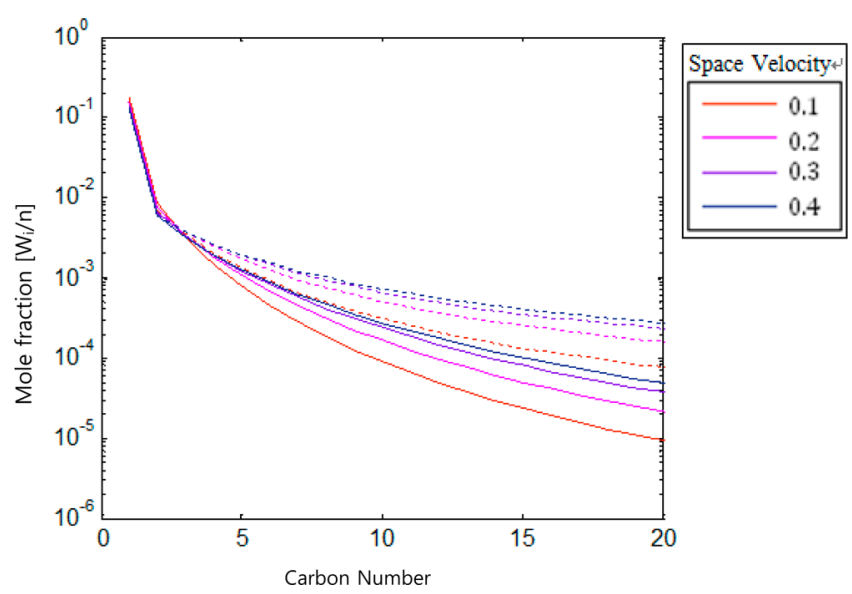

Figure 9. Effect of space velocity on carbon number distributions: solid lines, paraffins; dotted lines, olefins.

velocity leads to higher hydrocarbon products, whereas the amount of light hydrocarbons slightly decreases with the increase in space velocity.

Figure 10 shows how the particle size affects the carbon number distribution of the products. Namely, catalysts with

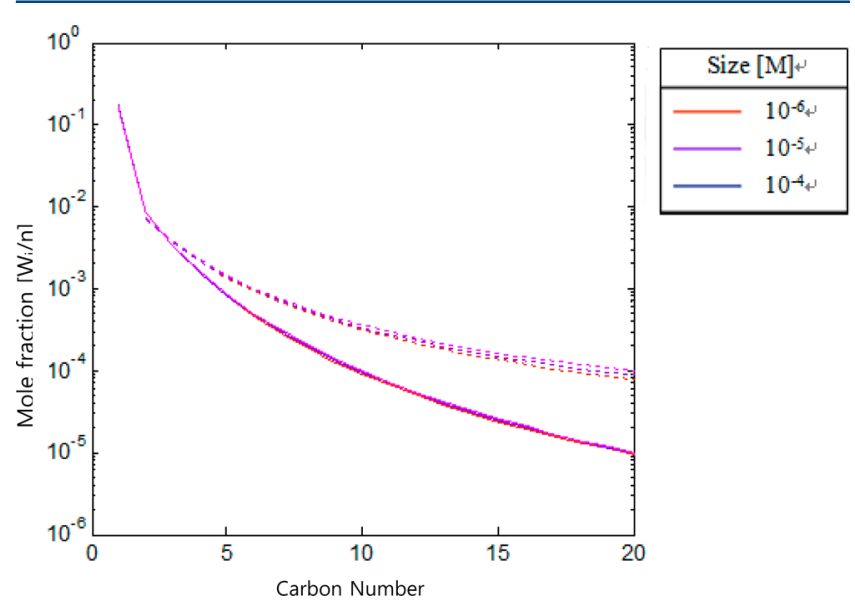

Figure 10. Particle size impact on carbon number: solid lines, paraffins; dotted lines, olefins.

a smaller particle size have a larger external surface area and, hence, a higher reaction rate per mass of catalyst. Therefore, it is reasonable to assume that catalysts with a smaller particle size may lead to higher hydrocarbon products, as far as it affords a pressure drop limit across the catalyst bed.

Figures 6-8 show the correlation between carbon numbers and the variables of temperature, pressure, and $\mathrm{H}_{2} / \mathrm{CO}$ ratio. It was found that increasing the $\mathrm{H}_{2} / \mathrm{CO}$ ratio and reaction temperature decreases the average carbon number of the products. Lastly, reaction temperature, pressure, and $\mathrm{H}_{2} / \mathrm{CO}$ ratio were evaluated simultaneously to maximize the gasoline $(\mathrm{C} 4-\mathrm{C} 8)$ and gas oil (C9-C20) products. The results showed that a reaction pressure of $1.5 \mathrm{MPa}$, a reaction temperature of $510 \mathrm{~K}$, and an $\mathrm{H}_{2} / \mathrm{CO}$ ratio of 1 in the feed stream were concluded as the optimized operating conditions to maximize gasoline and diesel products.

\section{SUMMARY}

Herein, a novel approach to the modeling of a F-T reactor is presented. Once the kinetic parameters were initially obtained from Yang's research, additional reaction-related parameters, such as catalyst size effect on diffusivity, active sites on the iron catalysts, and two-phase reactor design parameters, were embedded into the modeling. Then, these parameters were rigorously fitted to the experimental results that were obtained under wide range of operating condition by four different researchers. For the optimization of the kinetic parameters, a combination of a stochastic optimization algorithm and a deterministic optimization algorithm was used in this research. This method allowed us to shorten the overall computational time for optimization to reach to the global optimum point, without being trapped at a local optimum. Lastly, the operating parameters, such as reaction temperature, pressure, and $\mathrm{H}_{2} / \mathrm{CO}$ ratio in the reactor feed, were simultaneously optimized to maximize the yields of gasoline and diesel products.

The above approach allows us to develop a F-T reactor more systematically, enhancing the performance of a reactor. Furthermore, the product yields can be more accurately estimated than for any other conventional method that was developed so far.

\section{ACKNOWLEDGMENTS}

The $1^{\text {st }}$ and $4^{\text {th }}$ authors acknowledge that the research was funded in part by Inha University.

\section{AUTHOR INFORMATION}

\section{Corresponding Author}

*Tel: +82 32 8607461. Fax: +82 32 8720959. E-mail: sungwon. hwang@inha.ac.kr.

\section{Notes}

The authors declare no competing financial interest.

\section{NOMENCLATURE}

$A_{\sigma 1}=$ active site parameter

$D_{\mathrm{E}}=$ effective dispersion coefficient

$D_{\mathrm{e}}=$ effective diffusivity

$D_{\mathrm{G}}=$ gas-phase dispersion coefficient

$D_{\mathrm{L}}=$ liquid-phase dispersion coefficient

$D_{\mathrm{m}}=$ molecular diffusivity

$D_{\mathrm{r}}=$ reactor diameter $(\mathrm{m})$

$E_{\mathrm{CG}}=$ activation energy for chain growth $(\mathrm{kJ} / \mathrm{mol})$

$E_{\text {met }}=$ activation energy for methane formation $(\mathrm{kJ} / \mathrm{mol})$

$E_{\mathrm{o}}=$ activation energy for olefin formation $(\mathrm{kJ} / \mathrm{mol})$

$E_{\mathrm{p}}=$ activation energy for paraffin formation $(\mathrm{kJ} / \mathrm{mol})$

$E_{\mathrm{W}}=$ activation energy for WGS reaction $(\mathrm{kJ} / \mathrm{mol})$

$H=$ Henry's constant

$k=$ rate constant $(\mathrm{mol} / \mathrm{h})$

$K=$ equilibrium constant

$k_{\mathrm{CG}}=$ rate constant of chain growth $(\mathrm{mol} / \mathrm{g} \cdot \mathrm{s} \cdot \mathrm{bar})$

$k_{\mathrm{CO}}=$ rate constant of $\mathrm{CO}$ formation $(\mathrm{mol} / \mathrm{g} \cdot \mathrm{s} \cdot \mathrm{bar})$

$k_{\mathrm{p}}=$ propagation rate constant for alkyl mechanism $(\mathrm{h} / \mathrm{mol})$

$k_{\text {met }}=$ rate constant of methane formation $\left(\mathrm{MPa}^{-1} \cdot \mathrm{h}^{-1}\right)$

$k_{\mathrm{o}}=$ rate constant of olefin formation $(\mathrm{mol} / \mathrm{g} \cdot \mathrm{s} \cdot \mathrm{bar})$

$k_{\mathrm{p}}=$ rate constant of paraffin formation $(\mathrm{mol} / \mathrm{g} \cdot \mathrm{s} \cdot \mathrm{bar})$

$K_{\mathrm{W}}=$ equilibrium constant of WGS reaction for F-T $\left(\mathrm{MPa}^{-1}\right)$

$n=$ number of sub-PFRs

$P(n)=$ paraffin containing $n$ carbons $(\mathrm{mol})$

$P^{=}(n)=$ olefin containing $n$ carbons $(\mathrm{mol})$

$P_{\mathrm{CO}}=$ partial pressure of carbon monoxide $(\mathrm{MPa})$

$P_{\mathrm{H}_{2}}=$ partial pressure of hydrogen $(\mathrm{MPa})$

$P_{\mathrm{H}_{2} \mathrm{O}}=$ partial pressure of water $(\mathrm{MPa})$

$P e=$ Peclet number 
$P_{\mathrm{r}}=$ catalyst particle radius $(\mathrm{m})$

$R=$ ideal gas constant $(\mathrm{J} / \mathrm{mol} \cdot \mathrm{K})$

$\mathrm{SA}_{1}^{\prime}, \mathrm{SA}_{2}^{\prime}, \mathrm{SA}_{3}^{\prime}=$ catalyst parameters of active sites, $\theta$, for the model

$\mathrm{SA}_{\mathrm{E} 1}^{\prime}, \mathrm{SA}_{\mathrm{E} 2}^{\prime}, \mathrm{SA}_{\mathrm{E} 3}^{\prime}=$ catalyst parameters of active sites, $\theta$ and $\sigma$, for experimental data

$\mathrm{S}_{\theta}=$ active sites of iron-based catalysts

\section{Greek Letters}

$\alpha_{n}=$ chain growth probability factor of carbon number $n$

$\eta=$ effectiveness factor

$\phi=$ Thiele modulus

$\mu=$ solution viscosity

$\sigma=$ active site for the secondary hydrogenation reaction of 1 -

olefins

$\sigma 1=$ active site for active site parameter

$\theta=$ activation site for the primary F-T reaction and the secondary reaction participating in the chain growth of 1olefins

\section{Abbreviations}

LPG = liquefied petroleum gas

$\mathrm{GTL}=$ gas to liquid

WGS $=$ water gas shift

\section{REFERENCES}

(1) Jager, B. Stud. Surf. Sci. Catal. 1997, 219-224.

(2) Fleisch, T.; Sills, R;; Briscoe, M. J. Nat. Gas Chem. 2002, 1-14.

(3) van, d. L.; Beenackers, A. A. C. M.; Krishna, R. Chem. Eng. Sci. 1999, 21, 5013-5019.

(4) Botes, F. G. Int. Conf. Pet. Phase Behav. Fouling 2007, 1379-1389.

(5) Schulz, H.; Reidel, T.; Schaub, G. Top. Catal. 1995, 32, 3-4.

(6) Yang, J. Chem. J. Internet 2004, 6 (4), 27 ( http://www.mdpi.org/ cji/cji/2004/064027re.htm).

(7) Fernandes, F. A. N. Chem. Eng. Technol. 2005, 8, 930-938.

(8) Raje, A. P.; Davis, B. H. Catal. Today 1997, 3, 335-345.

(9) Guo, X.; Liu, Y.; Chang, J.; Bai, L.; Xu, Y.; Xiang, H.; Li, Y. J. Nat. Gas Chem. 2006, 2, 105-114.

(10) Wang, T.; Wang, J.; Jin, Y. Ind. Eng. Chem. Res. 2007, 18, 58245847.

(11) Ma, W.; Kugler, E. L.; Dadyburjor, D. B. Energy Fuels 2007, 4, $1832-1842$.

(12) Anderson, R.; Griffin, K.; Johnston, P.; Alsters, P. L. Adv. Synth. Catal. 2003, 4, 517-523.

(13) Dry, M. E. Catal. Lett. 1990, 1, 241-251.

(14) Dry, M. E.; Hoogendoorn, J. C. Catal. Rev.: Sci. Eng. 1981, 1, 265278.

(15) King, D. L.; Cusumano, J. A.; Garten, R. L. Catal. Rev.: Sci. Eng. 1981, 1, 233-263.

(16) Wendt, R.; Steiff, A.; Weinspach, P. Ger. Chem. Eng. 1984, 5, $267-$ 273.

(17) Deckwer, W.; Burckhart, R.; Zoll, G. Chem. Eng. Sci. 1974, 11, 2177-2188.

(18) Towell, G.; Ackerman, G. Axial mixing of liquid and gas in large bubble reactors. Chem. React. Eng., Proc. Eur. Symp., Sth 1972, 3, B3-1B3-13.

(19) Field, R. W.; Davidson, J. F. Trans. Inst. Chem. Eng. 1980, 4, $228-$ 236.

(20) Kawagoe, M. J. Jpn. Int. Econ. 1999, 1, 61-72.

(21) Ji, Y. Y.; Xiang, H. W.; Yang, J. L.; Xu, Y. Y.; Li, Y. W.; Zhong, B. Appl. Catal., A 2001, 1, 77-86.

(22) Pour, A. N.; Zare, M.; Zamani, Y. J. Nat. Gas Chem. 2010, 1, 3134.

(23) Bukur, D. B.; Okabe, K.; Rosynek, M. P.; Li, C.; Wang, D.; Rao, K.; Huffman, G. J. Catal. 1995, 2, 353-365.

(24) Van Der Laan; Gerard, P.; Beenackers, A. Catal. Rev. 1999, 3-4, 255-318.

(25) Mirzaei, A. A.; Vahid, S.; Feyzi, M. Adv. Phys. Chem. 2009, 151489. 